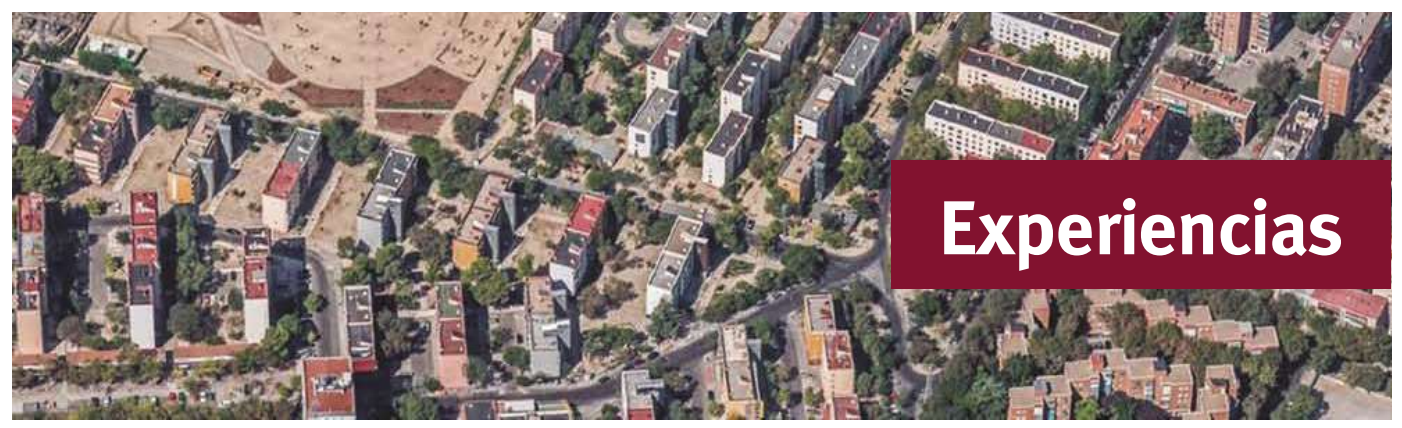

CIUDAD Y TERRITORIO

ESTUDIOS TERRITORIALES

ISSN(P): 1133-4762; ISSN(E): 2659-3254

Vol. LII, № 204, verano 2020

Págs. 349-356

https://doi.org/10.37230/CyTET.2020.204.11

CC BY-NC 4.0

(c) (1) ()

\title{
Área de Regeneración Urbana Ciudad de los Ángeles de Madrid
}

\author{
Rafael CóRdOBA-HERNÁNDEZ ${ }^{(1)}$ \\ Fernando CARMONA-MATEOS ${ }^{(2)}$ \\ Daniel Morcillo-Álvarez ${ }^{(3)}$ \\ Emilia ROMÁN-LÓPEZ ${ }^{(4)}$ \\ Carmen SÁnCHEZ-GueVARA ${ }^{(5) 1}$
}

(1) Profesor asociado del Departamento de Urbanística y Ordenación del Territorio de la Escuela Técnica Superior de Arquitectura de la Universidad Politécnica de Madrid.

Miembro de ONU-Habitat Planners for Climate Action (P4CA)

${ }^{(2)}$ Arquitecto e investigador del Instituto Juan de Herrera de la Escuela Técnica Superior de Arquitectura de la Universidad Politécnica de Madrid

(3) Profesor asociado del Departamento de Urbanística y Ordenación del Territorio de la Escuela Técnica Superior de Arquitectura de la Universidad Politécnica de Madrid

(4)Profesora Ayudante doctora del Departamento de Urbanística y Ordenación del Territorio de la Escuela Técnica Superior de Arquitectura de la Universidad Politécnica de Madrid

(5) Profesora Ayudante doctora del Departamento de Construcción y Tecnología Arquitectónicas de la Escuela Técnica Superior de Arquitectura de la Universidad Politécnica de Madrid

RESUMEN: El barrio madrileño de Ciudad de Los Ángeles (Distrito de Villaverde), de origen obrero, surgió de una promoción de viviendas construidas con escasos recursos, y enseguida empezaron a presentar patologías estructurales, constructivas y energéticas. Los vecinos, a través de su asociación ASVEYCO, impulsaron la declaración por parte del Ayuntamiento de Madrid del ámbito como Área de Rehabilitación Integral, y como Zona de Rehabilitación Integrada después. Esto permitió que entre 2005 y 2016 se desarrollase un proceso de rehabilitación tanto de gran parte de las viviendas como del espacio público, afrontando los problemas de habitabilidad, energéticos y de accesibilidad, entre otros, existentes en el ámbito.

\footnotetext{
${ }^{1}$ Este caso de estudio forma parte de un análisis mayor realizado como resultado del Convenio de Colaboración entre el Ministerio de Fomento y el Instituto Juan de Herrera (desarrollado a través del Grupo de Investigación en Arquitectura, Urbanismo y Sostenibilidad GIAU+S) en 2018 para la incorporación al "Observatorio de la Vulnerabilidad Urbana" del Informe Fórmulas innovadoras de gestión y financiación en actuaciones de regeneración de barrios.

Correo: rafael.cordoba@upm.es No ORCID: https://orcid.org/0000-0001-7878-2055;

Correo: f.carmona.mateos@outlook.es No ORCID: https://orcid.org/0000-0001-5119-435X;

Correo: daniel.morcillo@upm.es No ORCID: https://orcid.org/0000-0003-0521-8589;

Correo: emilia.roman@upm.es No ORCID: https://orcid.org/0000-0001-6746-2793;

Correo: carmen.sanchezguevara@upm.es No ORCID: https://orcid.org/0000-0002-9612-7633
} 


\section{Ciudad de los Ángeles neighborhood's Urban Regeneration Area (Madrid)}

ABSTRACT: Ciudad de Los Ángeles neighborhood (Villaverde District, Madrid) has a workers' origin and this generated a promotion of housing built with scarce resources that immediately began to present structural, constructive and energetic pathologies. ASVEYCO neighbors' association, promoted the declaration as Integral Rehabilitation Area and Integrated Rehabilitation Zone by the City Council of Madrid. Between 2005 and 2016 it allowed a process of rehabilitation of both a large part of the houses and the public space was developed, facing the problems of habitability, energy and accessibility, among others, existing in the field.

\section{CRÉDITOS DEL PROYECTO}

NOMBRE: Zona de Rehabilitación Integrada de Ciudad de los Ángeles

LOCALIZACIÓN: Barrio Ciudad de los Ángeles. Distrito Villaverde (Madrid)

FUNCIÓN: El proyecto abarca diferentes actuaciones que comprenden desde la Rehabilitación energética de viviendas, a través de la renovación de sus envolventes y la sustitución de las instalaciones de saneamiento, fontanería y electricidad para adecuarlas a la normativa y favorecer el ahorro de los consumos energéticos, hasta la mejora de accesibilidad en viviendas a través de la instalación de ascensores y la reurbanización del espacio público, atendiendo a la remodelación de los espacios interbloque más degradados y las mejoras de accesibilidad a las viviendas y al eje comercial, a través de la instalación de rampas para salvar los desniveles existentes

PROMOTOR: Ayuntamiento de Madrid (impulsado por la asociación de vecinos ASVEYCO)

AUTOR/ AUTORES Empresa Municipal de la Vivienda y el Suelo de Madrid

FECHA (DE PROYECTO Y DE EJECUCIÓN): 2005 - 2016

SUPERFICIE DE LA ACTUACIÓN: $59,6 \mathrm{Ha}$

COSTE/PRESUPUESTO: $63.508 .641 €$

NÚMERO DE VIVIENDAS AFECTADAS: 8.090 viviendas

ESTADO ACTUAL DE LA INTERVENCIÓN: Finalizado

CRÉDITOS DE LAS IMÁGENES: Rafael CóRdoba-HeRNÁNDEZ (2018)

\section{Contexto}

El barrio de Ciudad de los Ángeles está ubicado en la zona sur de Madrid, en el Distrito de Villaverde, y se desarrolla en dirección Norte Sur junto a la Avenida de Andalucía, entre la intersección de esta con la circunvalación M-40 y el cruce entre Villaverde Alto y Villaverde Bajo. Es colindante a los principales espacios industriales del sur de la ciudad, limitando con el polígono industrial que alojó la industria de automoción de la ciudad, la conocida como La Barreiros. De hecho, aquí se puede encontrar su origen, como una promoción residencial destinada a alojar a los trabajadores de estas fábricas. Su desarrollo se produce mediante un modelo de promoción que combina la iniciativa privada con la financiación pública, a través de las promotoras DIORVA y VIRELSA, además de otros promotores asociados a los industriales de la zona.

Es un espacio eminentemente residencial, que concentra un espacio dotacional en el núcleo de la urbanización, y que introduce espacios comerciales entre los bloques residenciales del sector. Los bloques residenciales, de entre cuatro y doce plantas, se agrupan básicamente en tres tipologías: bloque abierto, bloque en $\mathrm{H}$, y torre aislada. Las viviendas tienen mayoritariamente doble orientación (norte-sur) y una superficie útil media de $65 \mathrm{~m}^{2}$.

Asentado sobre terrenos arcillosos o de relleno, los edificios han sido objeto de refuerzos estructurales desde sus primeros años, pero no es hasta 2003 cuando la Asociación de Vecinos (ASVEYCO), asesorada por la Federación Regional de Asociaciones de Vecinos de Madrid (FRAVM) inicia el 


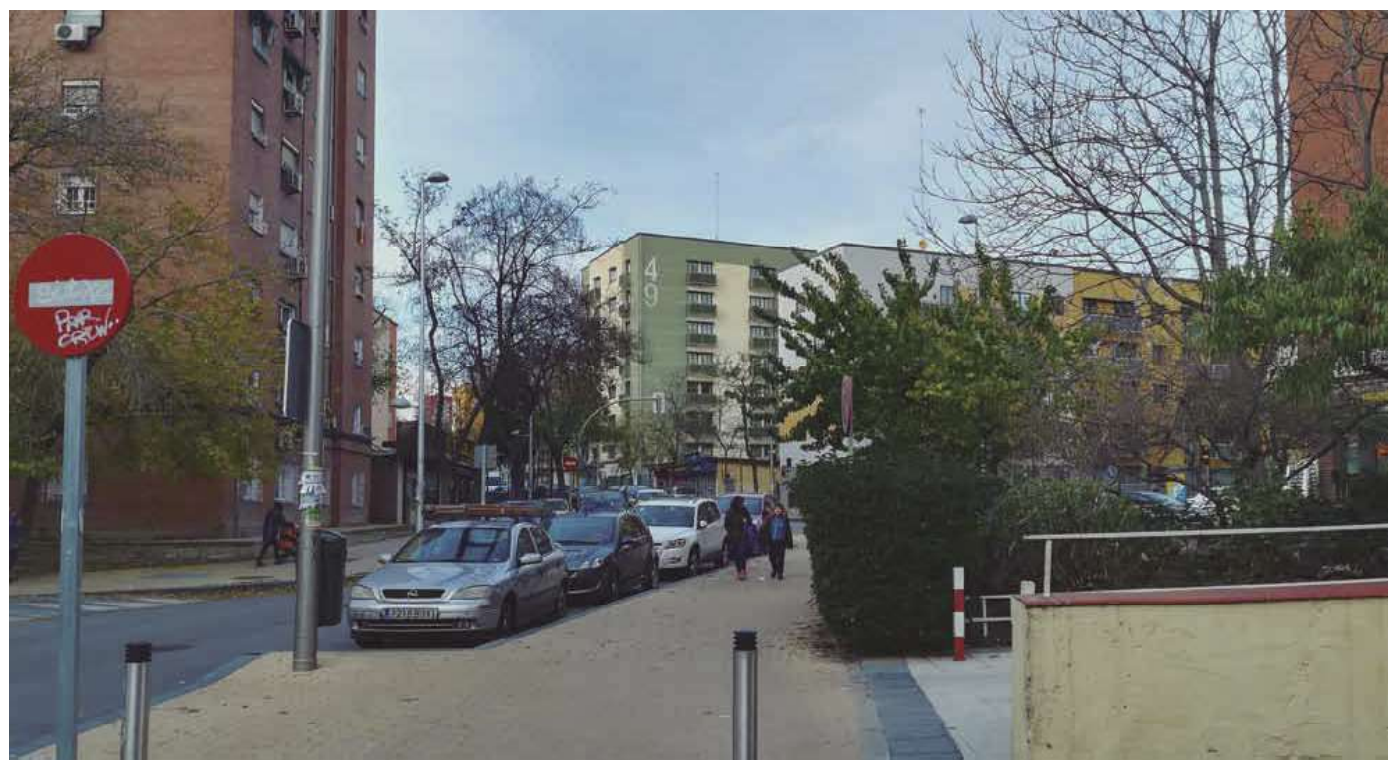

FIG. 1/ Imagen actual del barrio.

Fuente: Elaboración propia para Informe sobre Fórmulas innovadoras de Gestión y Financiación en actuaciones de Regeneración de Barrios.

proceso que culminaría en su rehabilitación. Las características del terreno, unido a los bajos costes de producción, han condicionado la construcción y vida de los edificios, llegando a presentar numerosos daños estructurales, constructivos, higrotérmicos y graves problemas de accesibilidad. Además, la urbanización ejecutada, aunque mostraba cierta calidad en el diseño, no resolvía los problemas de accesibilidad ocasionados por los desniveles del terreno.

El espacio contaba con una alta calidad ambiental gracias a la amplitud de espacios libres. Sin embargo, esto ha ocasionado dificultades en su conservación y en la solución de los desniveles que presenta. Además, su titularidad ha generado múltiples problemas de gestión ya que, aunque se realizaron las cesiones para la construcción de los sistemas generales, se mantuvo en propiedad privada el suelo de los espacios interbloques, escrituradas con cada vivienda en un porcentaje proporcional al suelo libre, por lo que la gestión de las cesiones tuvo que realizarse propietario a propietario. Los problemas de titularidad dificultaron también el mantenimiento de la urbanización.

\section{Estrategias}

La asociación de vecinos ASVEYCO fue la impulsora de la regeneración urbana del barrio, actuando de interlocutora, junto a la FRAVM, y centralizando la relación entre las comunidades de propietarios y la Comunidad de Madrid y el Ayuntamiento de Madrid, a los que se unió posteriormente la Empresa Municipal de la Vivienda y Suelo de Madrid (EMVS).

Las actuaciones llevadas a cabo fueron posibles gracias a su inclusión dentro del Plan Estatal de Vivienda 2005-2008, que estableció la delimitación de las Áreas de Rehabilitación Integral (ARI) como instrumento para afrontar la intervención integral en edificios e infraestructuras urbanas como práctica en la recuperación de tejidos barriales. Además, fue declarada por Orden de 6 de septiembre de 2005 de la Consejería de Medio Ambiente y Ordenación de Territorio de la Comunidad de Madrid Zona de Rehabilitación Integrada (ZRI), posibilitando su acceso a las ayudas previstas en el Plan de Vivienda 2005-2008 y el plan autonómico de vivienda y rehabilitación. A finales del mismo año, el 19 de diciembre de 2005, se firmó el convenio para su gestión durante el periodo 2005-2011. Este tiempo fue posteriormente ampliado hasta el 31 de diciembre de 2015, fecha en la que se da por concluida la intervención de rehabilitación de edificios y viviendas, mejora de infraestructuras y equipamiento comunitario. 


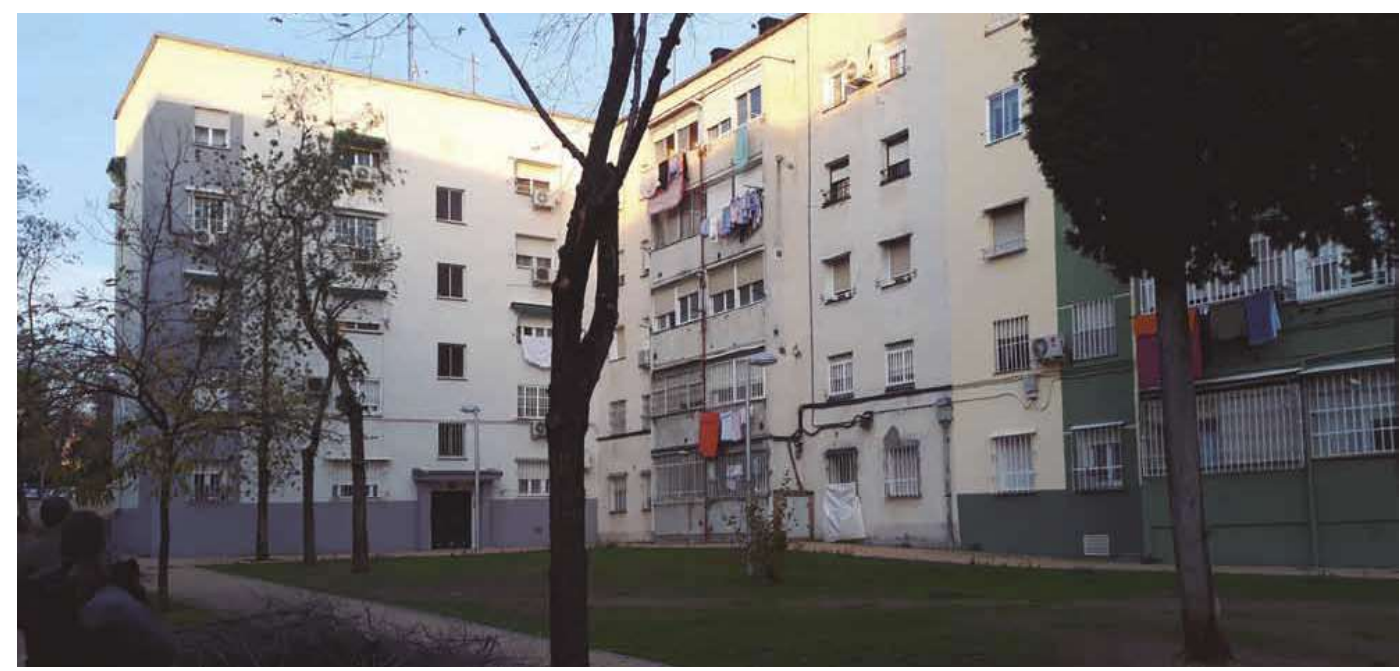

FIG. 2/ Imagen de la edificación original del barrio.

Fuente: Elaboración propia para Informe sobre Fórmulas innovadoras de Gestión y Financiación en actuaciones de Regeneración de Barrios.

Para determinar la extensión de la ZRI, se inició por parte de ASVEYCO un proceso de información y consulta a través de encuestas a todas las comunidades de propietarios sobre su deseo de formar parte de dicha ZRI. De estas consultas y posteriores reuniones se tomó la decisión de integrarse inicialmente en el proceso 240 de un total de 486 Comunidades (49,38\%). Consensuado este aspecto, se solicitó la declaración de ZRI en la Oficina Comarcal para la Rehabilitación de Edificios (OCRE) correspondiente, y la EMVS inició la redacción de una memoria de declaración que incluía la totalidad de los bloques, aunque no todos fueran a formar parte del proceso.

La declaración de este espacio como ZRI inicialmente y, como ARI después permitió el desarrollo de un programa de concesión de ayudas públicas directas, tanto a propietarios como inquilinos de viviendas. Su finalidad era acometer las obras necesarias de rehabilitación de elementos comunes de los edificios, así como la aportación de fondos públicos para la mejora del espacio urbano del barrio, mediante la renovación de infraestructuras y la transformación de la imagen del espacio público, muy deteriorada en el momento inicial de la intervención.

El espacio de intervención abarcaba un total de $59,6 \mathrm{Ha}$ y 8.090 viviendas distribuidas en edificios de diferentes alturas y tipologías: 3.708 viviendas (45,83\%) en bloques aislados, 2.890 viviendas $(35,72 \%)$ en bloques en $\mathrm{H}$ y las restantes 1.492 viviendas $(18,45 \%)$ en torres. De ellas, tan sólo los dos últimos grupos contaban con usos comerciales en planta baja.

Las actuaciones propuestas pretendían solventar distintas patologías estructurales, como la inadecuada cimentación para las características del terreno (arcilloso y de rellenos), que estaban causando problemas de estabilidad estructural al $25 \%$ de los edificios, y patologías constructivas en fachadas y cubiertas, que precisaban la renovación y el aislamiento de estas. En este sentido, en torno al $90 \%$ de los edificios, en el momento de la intervención, no presentaban las debidas condiciones en sus envolventes para favorecer el ahorro y la eficiencia energética. Además de las cuestiones constructivas anteriores, en la mayor parte de los edificios las instalaciones de saneamiento, fontanería y electricidad eran las originales y no se encontraban en buen estado ni adaptadas a la normativa vigente. En cuanto a cuestiones de accesibilidad, cerca del $50 \%$ de las viviendas presentaban problemas, ya que solamente los edificios de más de cinco plantas contaban con ascensor en el proyecto original.

Respecto al comportamiento higrotérmico de los edificios, la ausencia de medidas de aislamiento energético en el sistema constructivo ocasionaba numerosos daños, especialmente humedades y condensaciones en el interior de las viviendas, además de un elevado coste para la climatización de las mismas.

Por otro lado, debido a las numerosas intervenciones puntuales producidas, tanto sobre el espacio público como sobre las fachadas de los edificios, habían terminado generando una imagen fragmentada del espacio, que no favorecía la construcción de una identidad clara de barrio. A esto se unía que, dada la titularidad privada del suelo de los interbloques, que impedía la intervención y el mantenimiento de 


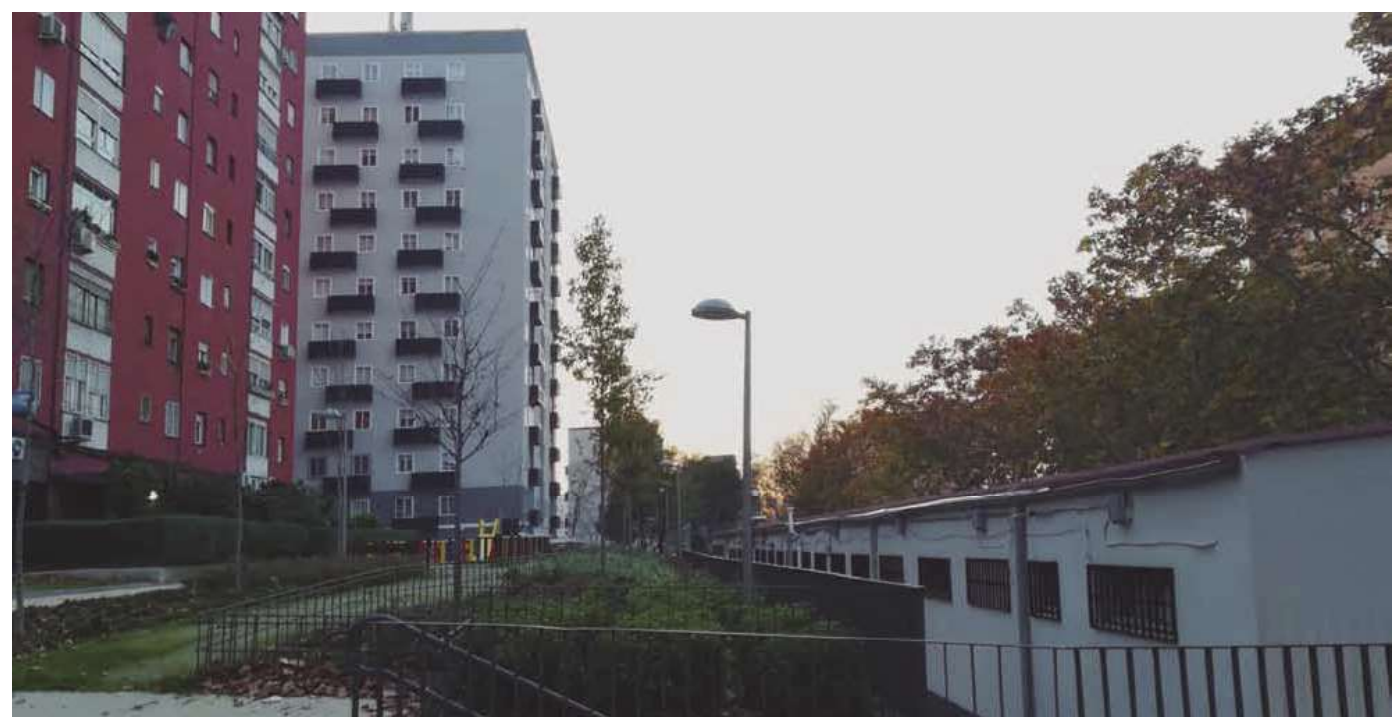

FIG. 3/ Imagen del espacio público del barrio.

Fuente: Elaboración propia para Informe sobre Fórmulas innovadoras de Gestión y Financiación en actuaciones de Regeneración de Barrios.

los servicios municipales, estos espacios inicialmente ajardinados se habían ido convirtiendo en zonas terrizas carentes de calidad ambiental para su adecuado uso.

Las intervenciones necesarias para solventar estos problemas fueron de la mano del planeamiento vigente de la ciudad (véase FIG. 4). Estas se centraron en la mejora de las condiciones de habitabilidad higrotérmica con la renovación de envolventes, la eficiencia de las instalaciones al adecuarlas a normativa vigente del Código Técnico de la Edificación (CTE), solucionar los problemas de accesibilidad interna por la instalación de ascensores, y corregir las condiciones de accesibilidad en la urbanización, con la sustitución de escaleras exteriores por rampas.

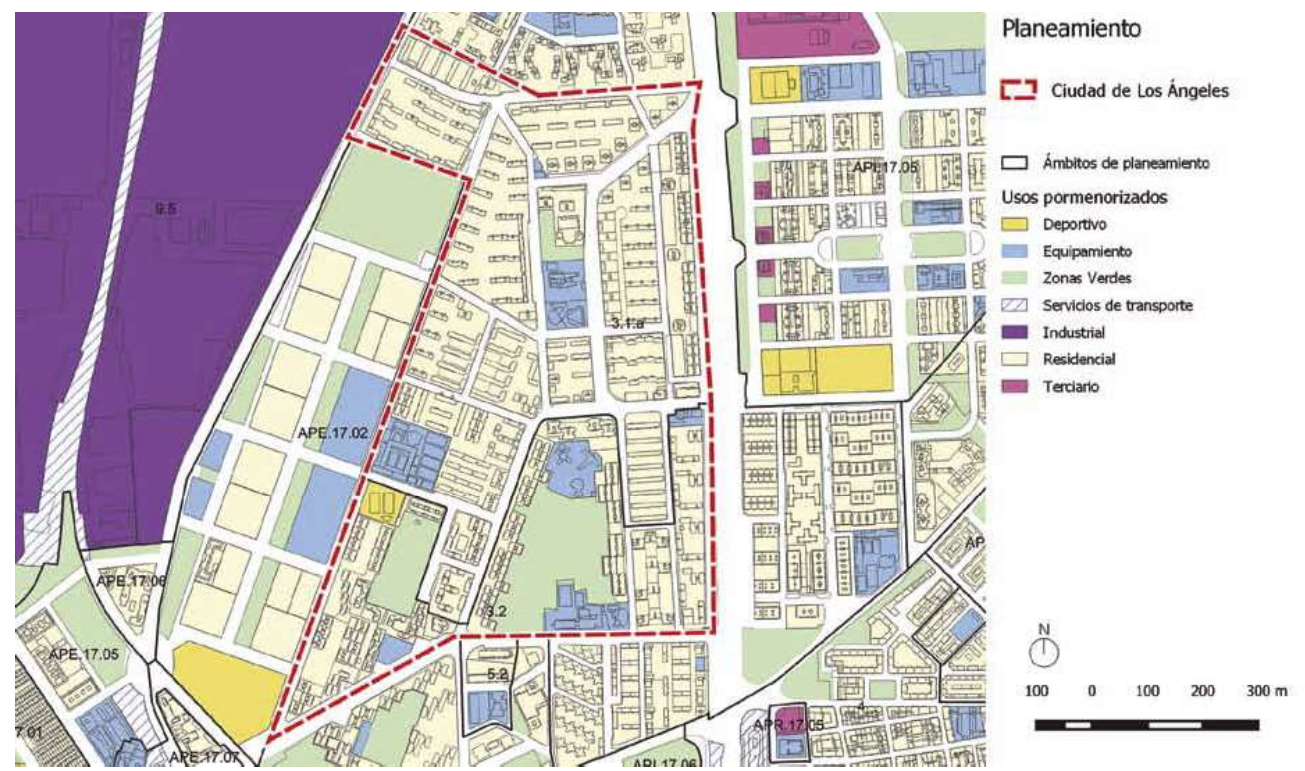

FIG. 4/ Relación del ámbito de intervención con la regulación urbanística vigente del PGOU 1997.

Fuente: Elaboración propia para Informe sobre Fórmulas innovadoras de Gestión y Financiación en actuaciones de Regeneración de Barrios. 


\section{Financiación y Gestión}

La declaración del área recogía una clara intención de fomentar la iniciativa privada y dirigir la rehabilitación de forma integrada, impidiendo a las administraciones públicas una intervención directa debido al alto porcentaje de las viviendas de titularidad privada. En este sentido, el papel de ASVEYCO se hizo imprescindible para garantizar el éxito en su ejecución. La asociación delegó la gestión de la rehabilitación a LARCOVI, empresa dedicada a la gestión de cooperativas, servicios integrales de rehabilitación y de remodelación de barrios. De forma mucho más activa, los vecinos intervinieron durante el proceso de reurbanización participando en la toma de decisiones sobre las zonas de actuación, así como la localización de las áreas de aparcamiento, las zonas infantiles y el tipo de vegetación.

Pese a no existir un organismo concreto de participación, durante la intervención se realizaron múltiples actuaciones para conocer la opinión y demandas vecinales, especialmente a través de encuestas y jornadas informativas al inicio del proceso, así como con la organización de debates puntuales para tomar decisiones concretas durante la actuación, como la selección de las zonas de la urbanización más degradadas y sobre las que se iba a intervenir.

La parte de gestión pública se realizó a través de la EMVS, en función del Convenio suscrito con la Comunidad de Madrid quien, a través de la Dirección General de Urbanismo y Suelo supervisaba el proceso. La EMVS actuó como Ente Gestor del Área de Rehabilitación y, por tanto, tuvo encomendada la gestión, tramitación y canalización de las ayudas públicas, tanto de la Comunidad de Madrid como del Ministerio de Fomento para este espacio. Además, hasta cuatro años antes del cierre de la intervención, tenía también la encomienda de la gestión de las ayudas municipales otorgadas a cargo de la Convocatoria Municipal de Ayudas a la Rehabilitación. Para ello ubicó una oficina de gestión en el propio ámbito, facilitando así la canalización de consultas y demás trámites con los propios vecinos.

Durante la única fase de gestión de este proyecto, según la documentación técnica facilitada por la EMVS de Madrid $^{2}$, se gestionaron un total de 63.508.641€ para la totalidad de la intervención. La principal partida presupuestaria fue la destinada a rehabilitación, con un coste aproximado de 46.991.176 $€$. De esta, prácticamente la mitad provino de los agentes privados $(42,46 \%)$ mientras que el resto del coste fue subvencionado por las diferentes administraciones intervinientes $(13,86 \%$ estatal, $17,17 \%$ autonómico y $26,51 \%$ municipal).

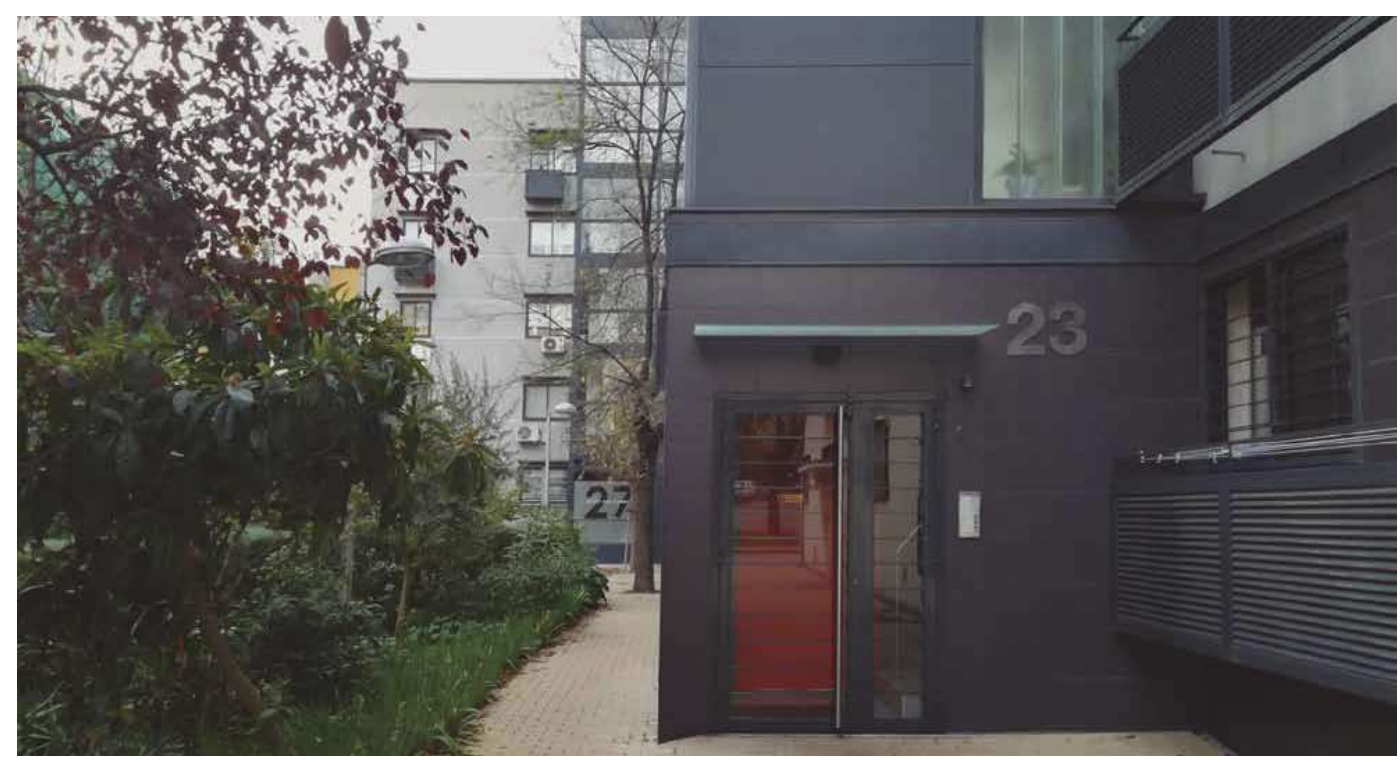

FIG. 5/ Imagen de la edificación rehabilitada del barrio.

Fuente: Elaboración propia para Informe sobre Fórmulas innovadoras de Gestión y Financiación en actuaciones de Regeneración de Barrios.

2 Precios 2016. 
Atendiendo a su tipología edificatoria, las cifras totales permiten estimar el coste de rehabilitación en bloques aislados en 33.464,06 €/viv., en bloques en $H$ en $31.165,54 € /$ viv., y en edificaciones en torre en 16.858,97 €/viv. El resto de los gastos, estimados en $16.517 .465 €$, fueron empleados en la reurbanización del espacio público. Esta inversión, que supone una repercusión de 2.114,53 €/viv., provenía de las distintas administraciones públicas implicadas, especialmente del propio Ayuntamiento, que financió más del $60 \%$ de las mismas $(10.523 .742 €)$.

Finalmente, cabe destacar que los requisitos establecidos para acceder a la concesión de ayudas públicas para la rehabilitación de las viviendas fueron principalmente técnicos, basados en aspectos energéticos, de accesibilidad o patologías en la edificación, y no económicos (no existían criterios de ingresos máximos). Para ello, el primer paso necesario fue la solicitud para realizar, por parte de la EMVS, un informe técnico para evaluar el estado del edificio y establecer los criterios de actuación más adecuados. Estos informes fueron realizados por los servicios técnicos de la Oficina de Ciudad de Los Ángeles, y aportaban a los solicitantes una relación de las obras obligatorias y recomendadas para poder acogerse a dichas ayudas. A partir de este informe, los equipos técnicos de las comunidades de propietarios redactaban un Proyecto de Ejecución que contenía todos los requisitos exigidos para la recepción de las ayudas.

\section{Resultados}

Los resultados de la intervención se evalúan mediante la metodología desarrollada por el Departamento de Urbanística y Ordenación del Territorio de la Universidad Politécnica de Madrid en la Estrategia para el diseño y la evaluación de planes y programas de regeneración urbana integrada en el marco del Plan Nacional de I+D+i para el período 2013-2015. Esta permite analizar una serie de aspectos pre y post operacionales, enmarcados en cuatro grandes grupos: Marco Urbano y Territorial; Diseño Urbano y Medio Ambiente Local; Edificación, y Socioeconómico. El trabajo de campo y las entrevistas desarrolladas para la elaboración del Informe Técnico sobre Fórmulas innovadoras de gestión y financiación en actuaciones de regeneración de barrios permiten afirmar que no hubo intervención en el campo socioeconómico. En el resto de políticas analizadas, se desprende una valoración positiva, ya que todos los aspectos evaluados se valoran, cuanto menos, igual que en la propuesta previa a la intervención.
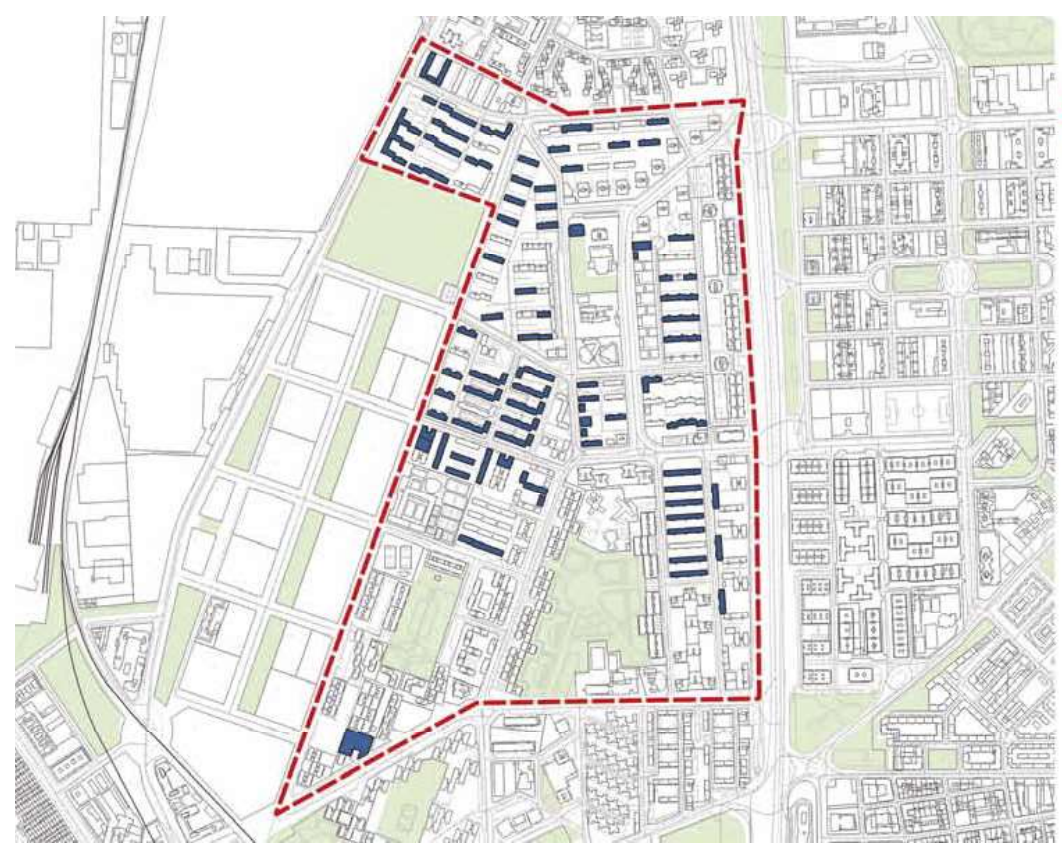

Financiación

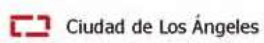

Edificios rehabilitados

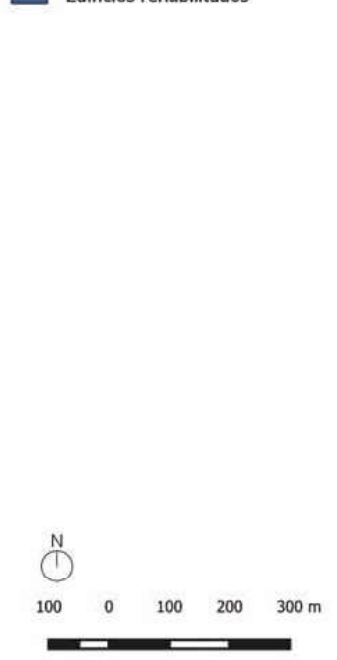

FIG. 6/ Localización de los edificios rehabilitados.

Fuente: Elaboración propia para Informe sobre Fórmulas innovadoras de Gestión y Financiación en actuaciones de Regeneración de Barrios. 
En el Marco Urbano y Territorial, inicialmente sólo estaba previsto trabajar sobre la Variedad y complejidad del entorno urbano y Patrimonio e identidad. Finalmente, la actuación consideró, también, aspectos de Integración del área urbana y Equilibrio del modelo urbano. Así, algunas de las soluciones propuestas en temas de urbanización fueron implementadas a lo largo del proceso de ejecución del ámbito, dado que estas no formaban parte de la declaración inicial.

En el área de Diseño Urbano y Medio Ambiente Local, tan sólo se consideraban aspectos relacionados con el Paisaje urbano y seguridad, Soporte del espacio público e Infraestructuras y servicios. Sin embargo, el resultado final de la intervención no muestra cambio en estos aspectos, pero sí la incorporación de aspectos como la Accesibilidad y movilidad y el Compromiso ambiental que, aunque inicialmente no estaban trabajados, fueron implementados en los resultados de forma satisfactoria y mejorable respectivamente.

También se realizaron intervenciones ligadas al área de Edificación. La incorporación de aspectos ligados a la sostenibilidad no estaba contemplada en la declaración del ámbito, pero sí fue considerada en la ejecución de las obras y soluciones propuestas, algunas de estas, como la instalación de placas solares $\mathrm{u}$ otras soluciones similares, finalmente no pudieron ser incorporadas al proceso. Además durante la ejecución se planteó la realización de tres experiencias piloto ligadas a programas europeos de financiación, pero finalmente tampoco fueron ejecutados.

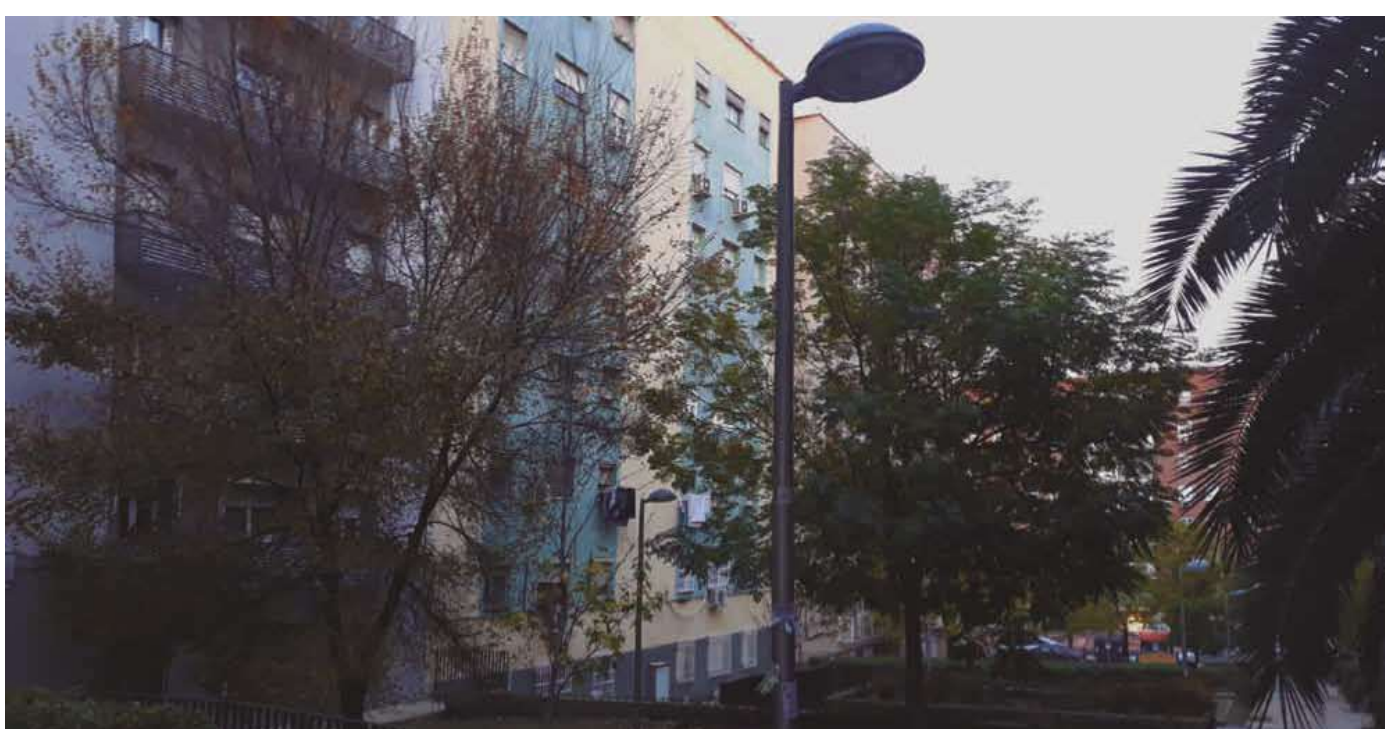

FIG. $7 /$ Imagen del espacio interbloque.

Fuente: Elaboración propia para Informe sobre Fórmulas innovadoras de Gestión y Financiación en actuaciones de Regeneración de Barrios.

\section{Bibliografía}

Hernández Aja, Agustín, \& al. (2016): Recuperando la ciudad. Estrategia para el diseño y la evaluación de planes programas de regeneración urbana integrada. Instituto Juan de Herrera, Madrid. ISBN 978-84-9728-518-6. Versión accesible en: http://oa.upm.es/43837/

HeRnÁndez Aja, Agustín, \& al. (2018): Fórmulas innovadoras de gestión y financiación en actuaciones de regeneración de barrios. Monografía (Informe Técnico). Ministerio de Fomento. Versión accesible en: https://www.fomento.es/arquitectura-vivienda-y-suelo/urbanismo-y-politica-de-suelo/observatorio-de-la-vulnerabilidad-urbana/informe-formulas-innovadoras-gestion-financiacion-actuaciones-regeneracion-barrios

LóPEZ MESA, Belinda (coord.) (2018): Nuevos enfoques en la rehabilitación energética de la vivienda hacia la convergencia europea. Edita Prensas de la Universidad de Zaragoza. Colección Cátedra Zaragoza Vivienda. ISBN 978-84-17358-41-9, 326 páginas. Versión accesible en:

https://catedrazaragozavivienda.wordpress.com/2019/01/17/libro-nuevos-enfoques-en-la-rehabilitacion-energeticade-la-vivienda-hacia-la-convergencia-europea-la-vivienda-social-en-zaragoza-1939-1979/

Morcillo Álvarez, Daniel \& Arjona Martín, Cristina \& Martín Acosta, Nieves (2016): "Recuperando la periferia. La rehabilitación energética de Ciudad de los Ángeles en Madrid". Ciudad y territorio: Estudios territoriales, ISSN 1133-4762, n¹87, págs. 57-76. Versión accesible en: https://apps.fomento.gob.es/CVP/handlers/pdfhandler.ashx?idpub=BP1015 